\title{
A radiation hybrid framework map of bovine chromosome 13
}

\author{
J. Schläpfer, Y. Yang, C. Rexroad III \& J. E. Womack
}

Received 2 June 1997; received in revised form and accepted for publication by H. Macgregor 1 September 1997

\begin{abstract}
In this paper we present a 5000-rad radiation hybrid framework map of bovine chromosome 13 (BTA13) containing 13 loci, including five conserved genes and eight polymorphic microsatellites. All framework markers are ordered with odds greater than 1000:1. Furthermore, we present a comprehensive map of BTA13 integrating 11 genes and 16 microsatellites. The proposed order is in general agreement with the recently published medium-density linkage maps. A model of five blocks of genes with conserved order between human, mouse and cattle is presented.
\end{abstract}

Key words: cattle, framework map, gene mapping, radiation hybrid, whole genome

\section{Introduction}

Radiation hybrids (RHs) were first developed by Goss \& Harris (1975). This somatic cell hybrid technique has since been applied extensively in human genome mapping (e.g. Walter et al. 1994, Dib et al. 1996). The principal advantage of RHs lies in the fact that polymorphic as well as non-polymorphic markers can be mapped, and therefore conserved anchor loci and other type I loci (O'Brien et al. 1993) can be integrated with existing meiotic maps composed of highly polymorphic microsatellites (for review see Walter \& Goodfellow 1993).

The genome mapping effort is not limited to human and mouse. Tremendous progress has been made in recent years, for example, in mapping the bovine genome. Second-generation, medium-density bovine linkage maps are now published (Barendse et al. 1997, Kappes et al. 1997). In these maps 1600 loci, most of which are microsatellites, cover more than $95 \%$ of the bovine genome. The average interval size between two markers has been reduced to less than 2.5 centiMorgans (cM). However, although 160 DNA markers that are located in or near a coding sequence are presented in the map by Barendse et al. (1997), a major disadvantage of the genetic linkage maps is still their lack of a sufficient number of type I markers.

J. Schläpfer (corresponding author, present address: Institute of Animal Breeding, University of Berne, Bremgartenstrasse 109a, CH-3012 Berne, Switzerland. Tel: $(+41) 31$ 6312320; Fax: $(+41)$ 31 6312640; Email: schlaepf@itz.unibe.ch), Y. Yang, C. Rexroad III and J.E. Womack are at the Department of Veterinary Pathobiology, College of Veterinary Medicine, Texas A\&M University, College Station, Texas 77843, USA.
For the mapping of economic trait loci (ETL) to bovine chromosome regions and ultimately the identification and cloning of the actual gene(s) responsible for the trait of interest, comparative gene mapping relative to the human and mouse genome plays an increasingly important role owing to the existence of high-resolution gene maps in the two later species. Although conservation of synteny between cattle and human, and to a slightly lesser extent cattle and mice, is extensive (Womack \& Moll 1986, Hayes 1995, Solinas-Toldo et al. 1995, Chowdhary et al. 1996), gene order is not consistently conserved. However, the extrapolation of data from map-rich genomes in a 'positional candidate cloning' (Collins 1995) approach to cattle will require the establishment of the linear order of comparative anchor loci and the definition of the boundaries of conserved gene order. RH mapping is a potentially powerful tool for building high-resolution ordered comparative maps of the bovine genome integrated with extensive bovine linkage maps.

A 5000-rad bovine whole-genome radiation hybrid (WG-RH) panel has recently been developed in our lab (Womack et al. 1997). The present study made use of this panel and was focused on bovine chromosome 13 (BTA13). Somatic cell hybrid mapping (Womack \& Moll 1986) and Zoo fluorescence in situ hybridization (FISH) studies (Hayes 1995, Solinas-Toldo et al. 1995, Chowdhary et al. 1996) have shown BTA13 to be homologous to parts of the human chromosomes 10 and 20 (HSA10 and HSA20), which in turn are, among others, represented on mouse chromosome 2 (MMU2). Our goal was the development of an ordered comparative map of anchor loci (O'Brien et al. 1993) and additional type I marker loci, previously assigned to BTA13, by analysis of RHs. Based on our findings we attempted to describe possible blocks of chromosomal rearrangements in cattle as compared with the human and mouse gene orders. The degree of concordance between the bovine WG-RH map and published meiotic maps was determined by integrating these type I loci with existing BTA13 linkage maps.

\section{Material and methods}

\section{Construction and characterization of the WG-RH} panel

The construction of this cattle-hamster WG-RH panel is described elsewhere (Womack et al. 1997). Briefly, JEW 38, a bovine fibroblast cell line was irradiated with $5000 \mathrm{rad}$ 


\section{J. Schläpfer et al.}

(185 rad/min) at room temperature using a ${ }^{60} \mathrm{Co}$ source and subsequently polyethylene glycol (PEG) fused to A23, a thymidine kinase-deficient $\left(\mathrm{TK}^{-}\right)$hamster recipient cell line, which allows selection of hybrids using hypoxanthine-aminopterin-thymidine (HAT) medium. Rapid selection against bovine cells was facilitated with ouabain.

A total of 101 HAT-resistant WG-RH clones were picked and transferred to tissue culture flasks and harvested at confluence for DNA extraction. DNA of the first 74 hybrids was tested for the presence of bovine chromosome fragments using the bovine short interspersed nuclear element (SINE) sequence (Lenestra et al. 1993) derived primer BOVA (5' CAG AGT CGG ACA CGA CTG AA). Bovine DNA was amplified in 69 hybrids (data not shown). All 101 hybrids were then tested using a bovine-specific primer pair for the thymidine kinase (TK) gene (Y. Yang, unpublished data). As A23 is deficient in the TK gene, the hybrid cells need the bovine gene substitution in order to survive in the HAT-selective medium. All but one hybrid (RH34.0) amplified the bovine-specific TK fragment. However, this cell line clearly showed several fragments amplified with the BOVA primer. We assumed that RH34.0 is an $\mathrm{A} 23 \mathrm{TK}^{+}$revertant that contains a bovine chromosome fragment. RH34.0 was therefore excluded from further analysis. DNA of the remaining $100 \mathrm{RHs}$ was subsequently typed for all 27 BTA13 loci.

\section{Loci}

The 11 type I loci previously assigned to BTA13 were: argininevasopressin, neurophysin II $(A V P)$ and prepro-oxytocin, neurophysin I (OXT, Dietz et al. 1992); casein kinase 2, alpha 1 polypeptide (CSNK2A1, Gao et al. 1997); guanidine nucleotide binding protein, alpha subunit (GNAS1, Gao \& Womack 1993); haemopoietic cell kinase $(H C K)$ and prion protein (PRNP, Womack et al. 1991); interleukin 2 receptor alpha (IL2RA) and vimentin (VIM, Threadgill \& Womack 1991); superoxide dismutase-1, soluble like (SOD1L, Gallagher et al. 1992); thrombomodulin (THBD) and phosphatidylinositol-specific phospholipase C (PLC-II, Schläpfer et al. 1997a). As many BTA13 microsatellite markers as possible were included in the analysis as they became available, which led to a total of 16 microsatellites (Table 1) selected from published maps.

\section{PCR primers}

MacVector Version 4.1.4 Sequence Analysis Software was used for the primer design. PCR primers for the type I loci were designed either directly from published bovine sequences or based on information of conserved exon sequences from human or mouse homologous genes (Table 2). The primers for CSNK2A1 have previously been published (Gao 1996). Microsatellite primers were selected from published BTA13 linkage maps (Table 1).

\section{PCR conditions}

PCR was performed in a Perkin Elmer GeneAmp System 9600 thermocycler. Standard PCR conditions were: $10 \mathrm{mM}$ Tris- $\mathrm{HCl}$, $1.5 \mathrm{mM} \mathrm{MgCl}_{2}, 50 \mathrm{mM} \mathrm{KCl}, \mathrm{pH} 8.3\left(20^{\circ} \mathrm{C}\right), 100 \mu \mathrm{M}$ each dNTP, $0.3 \mu \mathrm{M}$ each primer, $50 \mathrm{ng}$ genomic DNA, and 0.5 units of Taq polymerase (Boehringer Mannheim, Indianapolis, IN, USA) in a total reaction volume of $10 \mu \mathrm{l}$. The standard PCR protocol consisted of a 3-min denaturation step at $95^{\circ} \mathrm{C}$, followed by $36-$ 40 cycles of $30 \mathrm{~s}$ at $95^{\circ} \mathrm{C}, 15-30 \mathrm{~s}$ at the respective annealing temperature (Tables 1 \& 2), and $30-60 \mathrm{~s}$ extension at $72^{\circ} \mathrm{C}$. A final extension was performed for $5 \mathrm{~min}$ at $72^{\circ} \mathrm{C}$. The appropriate annealing temperature was optimized in preliminary experiments to yield specific amplification of the bovine product in a hamster background. A touchdown protocol (Don et al. 1991) was implemented for several microsatellite markers (Table 1) to further increase the specificity of the PCR. Amplification products were electrophoresed on $2 \%$ agarose or $4 \%$ NuSieve 3:1 (FMC, Rockland, ME, USA) gels containing ethidium bromide and then photographed. Each of the 27 markers was analyzed at least twice for the presence or absence of a bovine-specific product. Additional typings were performed in case of ambiguous findings.

Statistical analysis and generation of $\mathrm{RH}$ maps

The data obtained were of the three categories 'present', 'absent', or 'not typed'. The RHMAP statistical software

Table 1. Microsatellites used in $\mathrm{RH}$ analysis of BTA13

\begin{tabular}{lllll}
\hline Symbol & GenBank access \# & Reference & Annealing temp. & Fragment size in bp \\
\hline ETH7/D13S1 & Z22746 & Barendse et al. (1994) & 68 & $\sim 380$ \\
TGLA23/D13S2 & - & Bishop et al. (1994) & $65 \rightarrow 58^{*}$ & $\sim 110$ \\
TGLA6/D13S3 & - & Ma et al. (1996) & 60 & $\sim 170$ \\
CSSM30/D13S5 & - & Barendse et al. (1994) & $66 \rightarrow 64^{*}$ & $\sim 155$ \\
HUJ616/D13S6 & M88250 & Barendse et al. (1994) & $65 \rightarrow 60^{*}$ & $\sim 125$ \\
AGLA232/D13S10 & - & Bishop et al. (1994) & $68 \rightarrow 64^{*}$ & $\sim 180$ \\
BL42/D13S11 & - & Bishop et al. (1994) & $68 \rightarrow 65^{*}$ & $\sim 230$ \\
BMC1222/D13S13 & G19106 & Bishop et al. (1994) & $\sim 285$ \\
JAB3/D13S16 & X98437 & Barendse et al. (1997) & 60 & $\sim 230$ \\
ILSTS86/D13S17 & L37238 & Ma et al. (1996) & 60 & $\sim 190$ \\
URB07/D13S22 & - & Ma et al. (1996) & 58 & $\sim 190$ \\
URB58/D13S24 & - & Ma et al. (1996) & $\sim 165$ \\
TGLA381/D13S26 & - & Kappes et al. (1997) & $\sim 180$ \\
UWCA25/D13S29 & L35541 & Barendse et al. (1997) & $66 \rightarrow 62^{*}$ & $\sim 110$ \\
MILSTS77/D13S32 & L37274 & Ma et al. (1996) & 58 & $\sim 190$ \\
ILSTS59/D13S33 & L37266 & Ma et al. (1996) & 60 & $\sim 180$ \\
\hline
\end{tabular}

*Touchdown procedure (Don et al. 1991).

- no GenBank access \# available. 
Table 2. Primers for type I loci used in $\mathrm{RH}$ analysis of $B T A 13$

\begin{tabular}{|c|c|c|c|c|c|}
\hline Symbol & $\begin{array}{l}\text { GenBank } \\
\text { access \# }\end{array}$ & Primer sequence & Reference & $\begin{array}{l}\text { Annealing } \\
\text { temp. }\end{array}$ & $\begin{array}{l}\text { Fragment } \\
\text { size in bp }\end{array}$ \\
\hline IL2RA & U24226 & $\begin{array}{l}\text { F'GCTGATGTGGAGGTTCTTCGTATTC } \\
\text { R'TCGGTGATGACTGAGGCAAAG }\end{array}$ & $\begin{array}{l}\text { Schläpfer et al. } \\
\text { This paper }\end{array}$ & $65 \rightarrow 60^{*}$ & $\sim 225$ \\
\hline VIM & L13263 & $\begin{array}{l}\text { F'GCCCAGATTCAAGAACAGCATG } \\
\text { R'CATTGTTGCGGTTAGCAGCTTC }\end{array}$ & This paper & 61 & $\sim 700$ \\
\hline CSNK2A1 & M93665 & & Gao (1996) & 60 & $\sim 2000$ \\
\hline AVP & X00503 & $\begin{array}{l}\text { F'GCCACGTCACTTCAGAGGGAAC } \\
\text { R'TCAGCTCCAGGTCGGACATG }\end{array}$ & $\begin{array}{l}\text { Schläpfer et al. } \\
\text { This paper }\end{array}$ & 61 & $\sim 225$ \\
\hline OXT & X58474 & $\begin{array}{l}\text { F'TCCACAGCACTTACCACCCCTAAC } \\
\text { R'CAGTTCATTGGCATGGCTGGTC }\end{array}$ & $\begin{array}{l}\text { Schläpfer et al. } \\
\text { This paper }\end{array}$ & 59 & $\sim 335$ \\
\hline PRNP & D26150 & 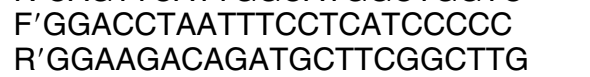 & $\begin{array}{l}\text { Schläfer et al. } \\
\text { This paper }\end{array}$ & 58 & $\sim 725$ \\
\hline THBD & M14657 & & Schläpfer et al. (1997a) & 60 & $\sim 180$ \\
\hline HCK & M16591 & $\begin{array}{l}\text { F'GCTGCCAACATCTTGGTCTCTG } \\
\text { R'AGCTGTCCACTTGATGGGGAAC }\end{array}$ & $\begin{array}{l}\text { Schläpfer et al. } \\
\text { This paper }\end{array}$ & 60 & $\sim 2000$ \\
\hline PLC-II & Y00301 & & Schläpfer et al. (1997a) & 60 & $\sim 200$ \\
\hline GNAS1 & $\begin{array}{l}\text { M21142 } \\
\text { J03647 }\end{array}$ & $\begin{array}{l}\text { F'TGACTGCCATCATCTTCGTGG } \\
\text { R'CAGCAAGGACTTTCTCAGCGAG }\end{array}$ & $\begin{array}{l}\text { Schläpfer et al. } \\
\text { This paper }\end{array}$ & 59 & $\sim 335$ \\
\hline SOD1L & M81129 & $\begin{array}{l}\text { F'TCTACTTGGTTGGGGCGTCTCTAG } \\
\text { R'CAAACTGATGGACGTGGAATCC }\end{array}$ & $\begin{array}{l}\text { Schläpfer et al. } \\
\text { This paper }\end{array}$ & 56 & $\sim 350$ \\
\hline
\end{tabular}

*Touchdown procedure (Don et al. 1991).

program version 2.01 and 3.00, consisting of the three fortran 77 programs RH2PT, RHMINBRK and RHMAXLINK (Boehnke et al. 1991, Lange et al. 1995), was used for data analysis.

RH2PT was first used to estimate marker retention frequencies. Two-point distance estimates were later used as references for the construction of the comprehensive marker map. Linkage groups were identified in which loci are linked on the basis of two-point lod scores of at least 2.0, 3.0, 4.0, 6.0 and 8.0. Finally, the program was used to identify markers with identical retention patterns. RHMINBRK was run with different subsets of loci in the stepwise ordering strategy. SAVMAX was increased until no change was observed in the respective locus orders. Results of the RHMINBRK analysis were again used as reference in developing the comprehensive map. Because of the large number of loci, RHMAXLINK was used in the stepwise ordering strategy with a SAVMAX setting of 9.00. The data were analyzed under both equal retention and centromeric retention models. The centromeric retention model resulted in locus orders that were in better agreement with the RHMINBRK computations and was used for further analyses. In a first step, all loci were used to develop a framework map of loci ordered with a relative likelihood of at least 1000:1 (ADDMIN 3.00). To add framework markers to both ends of the map, the markers were divided into two subsets and a framework marker in the central portion of the map was fixed as an end locus. RHMAXLINK was rerun with ADDMIN 3.00 with the respective subset towards the centromeric and the telomeric end of the map. All loci ordered with this level of support were then forced in this order (NFORCE in LNAMEA) and the program rerun to add loci with a level of support of at least 100:1 (ADDMIN 2.00). The additional loci ordered in this manner were added to the above forced order and the program run again with ADDMIN 0.00. The result of this last step, together with information derived from RH2PT as well as RHMINBRK analysis, led to the most probable comprehensive map.

\section{Results}

Of the 100 hybrids analyzed, 22 were negative and three were positive for all loci tested. The average retention frequency was $26.4 \%$ with the lowest for THBD $(16.5 \%)$ and the highest for AGLA232 (41.4\%). Seventy-five unique retention patterns for the 27 loci tested were observed. $A V P$ and $O X T$ were never discordant and were therefore treated as one locus (AVP/OXT). All 27 markers were part of one linkage group at lod score levels of 2.0, 3.0, 4.0, and 6.0. A lod score threshold of 8.0 resulted in four linkage groups, the first consisting of AVP/OXT, HCK, PRNP, VIM, THBD, GNAS1, CSNK2A1, SOD1L, MILSTS77, BL42, TGLA381, ILSTS86, ILSTS59, URB07, URB58, ETH7, UWCA25, and HUJ616. The second linkage group was composed of IL2RA, TGLA23, TGLA6, and BMC1222. CSSM30 and PLC-II were in the third linkage group and AGLA232 and JAB3 in linkage group four.

A framework map with 13 loci ordered with odds greater than 1000:1 was developed. This framework map consists of eight microsatellites and five type I loci (Figure 1). The linear order of loci in this framework map is: centromere - TGLA23 - IL2RA - ILSTS59 URB07 - URB58 - TGLA381 - SOD1L - ETH7 - BL42 - GNAS1 - HCK - PLC-II - AGLA232. The most probable comprehensive map is also given in Figure 1. However, in the comprehensive map, it was not possible to order BMC1222, VIM, MILSTS77, HUJ616, ILSTS86, THBD, UWCA25 and PRNP relative to the framework markers IL2RA and ILSTS59 and within the framework markers TGLA23 and URB07 with odds greater than 10:1. Four possible orders of the chromosome segment in question are given in Table 3. 
J. Schläpfer et al.

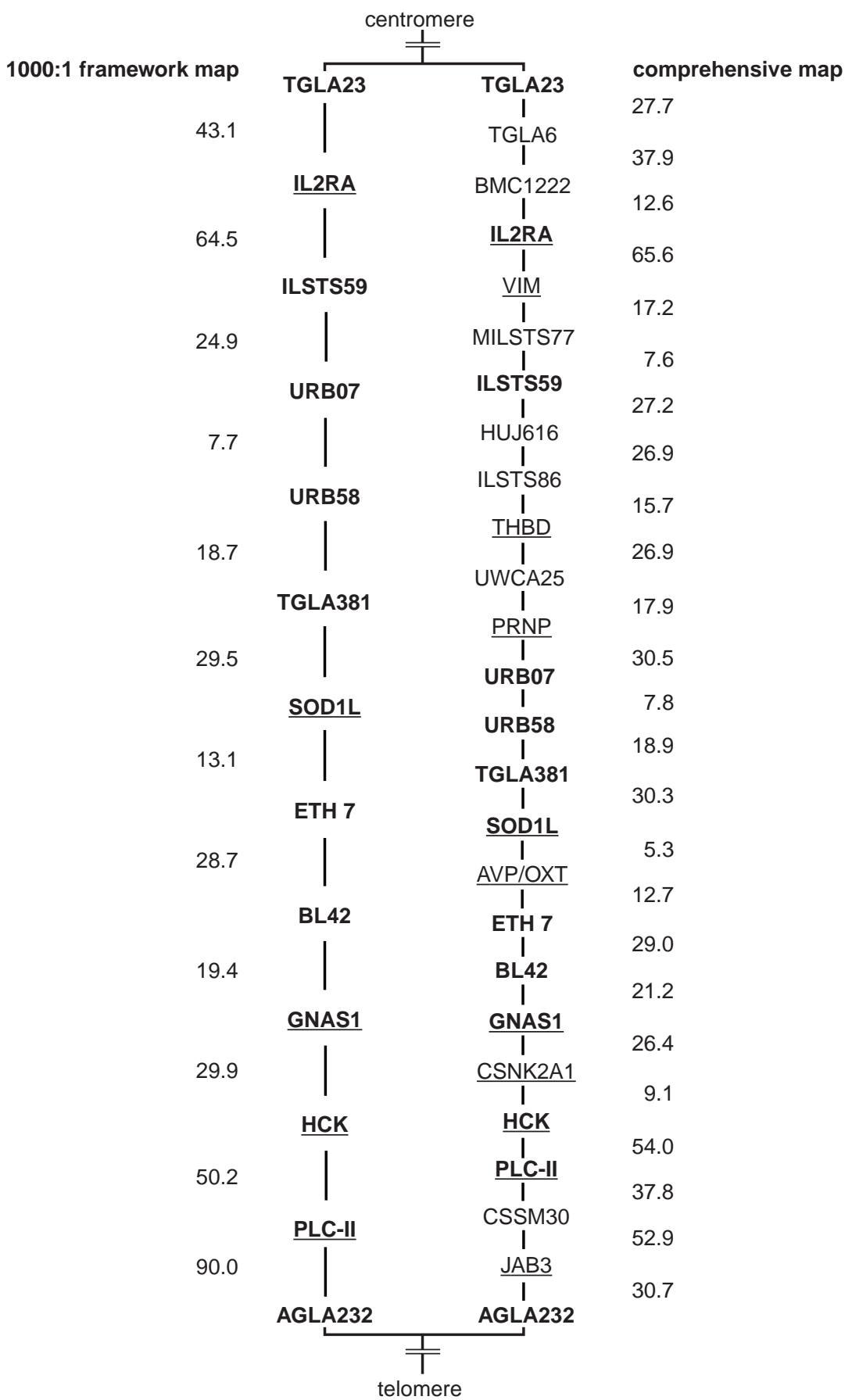

Figure 1. BTA13 framework map with $13 \mathrm{loci}$, all ordered with odds greater than 1000:1 (left), and a comprehensive map with 27 loci based on results from MAXLINK, RHMINBRK and RH2PT analysis (right). Framework markers are bold, type I loci are underlined. The comprehensive map spans a total distance of $650 \mathrm{CR}_{5000}$.

\section{Discussion}

We have constructed a 5000-rad WG-RH mapping panel consisting of 100 hybrids to provide a tool for the development of framework maps for each of the 30 bovine chromosomes. It was possible to develop a framework map of BTA13 consisting of 13 loci, all ordered with odds greater than 1000:1, as well as the most probable comprehensive map consisting of 27 loci.

An average marker retention frequency of $26.4 \%$ was found for the 27 BTA13 loci tested. The analysis of such a panel provides sufficient data to find the true marker 

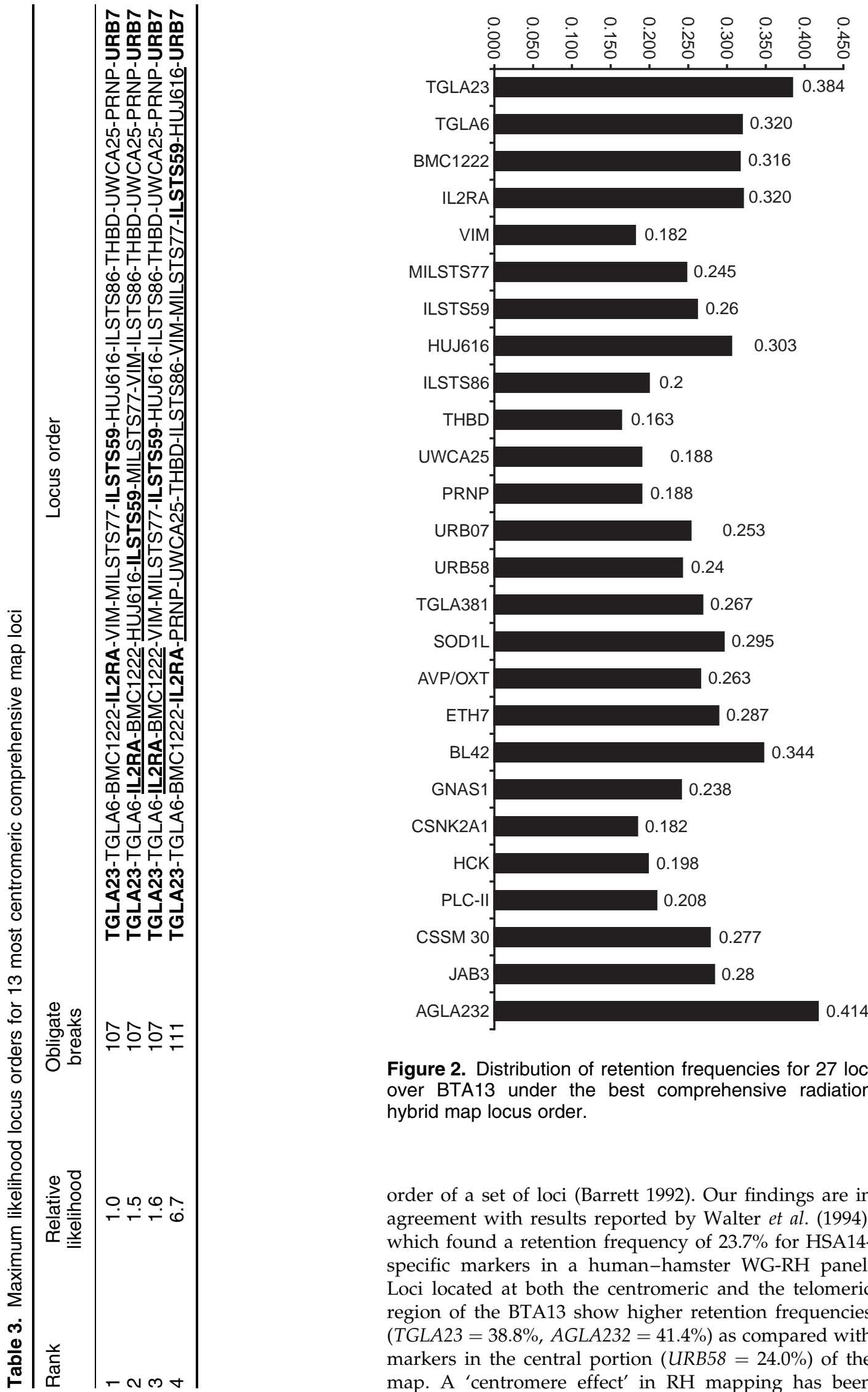

Figure 2. Distribution of retention frequencies for 27 loci over BTA13 under the best comprehensive radiation hybrid map locus order.

order of a set of loci (Barrett 1992). Our findings are in agreement with results reported by Walter et al. (1994), which found a retention frequency of $23.7 \%$ for HSA14specific markers in a human-hamster WG-RH panel. Loci located at both the centromeric and the telomeric region of the BTA13 show higher retention frequencies $($ TGLA23 $=38.8 \%$, AGLA232 $=41.4 \%)$ as compared with markers in the central portion (URB58 $=24.0 \%$ ) of the map. A 'centromere effect' in RH mapping has been 


\section{J. Schläpfer et al.}

described in human and mouse and is probably due to selection for centromeres that confer stability on chromosomal fragments (Ceccherini et al. 1990, Sefton et al. 1992). An increase in the retention frequency for markers near the telomere has also been noted (Ceccherini et al. 1990, Lawrence et al. 1991). Figure 2 illustrates the distribution of the retention frequencies over the chromosome segment covered, arranged in the most probable comprehensive map locus order.

Based on the multipoint distance estimates for the framework map, the loci in the central part of the chromosome segment covered are relatively evenly distributed, whereas toward the two ends of the map (ILSTS59 - IL2RA - TGLA23 and HCK - PLC-II AGLA232) the distances tend to increase. The uneven distribution of the selected loci along the chromosome becomes obvious at the centromeric third of the comprehensive map. The five loci HUJ616, ILSTS86, THBD, UWCA25, and PRNP have their most probable comprehensive map position between the two framework markers ILSTS59 and URB07. For the former five loci and the additional markers VIM, MILSTS77, and BMC1222 we found four possible orders with odds smaller than 10:1 in our comprehensive map (Table 3). The low level of support reveals a limited resolving power of the 5000-rad panel and is probably due to the clustering of loci in a distinct area on the chromosome, as sets of markers with considerable interval variation are generally more difficult to map than markers that are evenly spaced (Jones 1996).

The framework map indicates a distance of 24.9 centiRays (cR) between ILSTS59 and URB07. Under the most probable locus order of the comprehensive map this distance inflates to $145.1 \mathrm{cR}$. Inflation of the map length by adding markers to a map is also known in recombination-based linkage mapping, partially because of an increase in genotyping errors in marker-rich regions (Kappes et al. 1997). Typing errors reduce the ability to order loci and inflate estimates of interlocus distances (Lunetta et al. 1995). We found the main typing error problem in $\mathrm{RH}$ mapping to be the scoring of false-negative results in cases where only a bovinespecific PCR product was amplified. To reduce the risk of introducing typing errors, duplicate typing of every marker was performed before statistical analysis, as this results in a better probability of identifying the true order as one of the best orders (Lunetta et al. 1995). In some cases, mainly in the analysis of microsatellites, ambiguous results were observed between the two typings (data not shown). For those markers the typing was repeated until reproducible results were received, or the marker was called 'not typed' for a certain $\mathrm{RH}$ cell line.

The total length of the comprehensive BTA13 RH map between the markers TGLA23 and AGLA232 is $650 \mathrm{CR}_{5000}$. Barendse et al. (1997) found the two markers separated by $130 \mathrm{cM}\left(5 \mathrm{cR}_{5000} / \mathrm{cM}\right)$ and Kappes et al. (1997) indicate an interval of $79.5 \mathrm{cM}\left(8.2 \mathrm{cR}_{5000} / \mathrm{cM}\right)$. These data differ from the human-hamster WG-RH map (Walter et al. 1994) where $1 \mathrm{cM}$ is equivalent to $10 \mathrm{CR}_{3000}$. Assuming, that $1 \mathrm{cM}$ approximately equals $1 \mathrm{Mb}$, the $\mathrm{cR} / \mathrm{cM}$ ratios found in chromosome-specific human-hamster RH maps vary from $18 \mathrm{cR} 9000 / \mathrm{cM}$ (Richard et al. 1991) to $33 \mathrm{cR}_{6500} / \mathrm{cM}$ (Warrington et al. 1992). Our lower estimates might be due to an inaccurate estimation of either the length of the genetic maps or the RH map, and/or variation in chromosome and chromosome region-specific sensitivity to irradiation. Depending on the relative location of the microsatellites on BTA13, the $\mathrm{CR}_{5000} / \mathrm{cM}$ ratios, compared with the map by Kappes et al. (1997), varied from 3.3 for the interval TGLA23 - BMC1222 and 18.7 for ILSTS86 - TGLA381. Chromosome region-specific $\mathrm{cR} / \mathrm{cM}$ ratios have also been described in human (Raeymaekers et al. 1995). However, to allow an accurate comparison of distances derived from RH analysis with linkage mapping results, centiRays have to be transformed into physical distances by methods such as pulsed-field gel electrophoresis (PFGE) and yeast artificial chromosome (YAC) or bacterial artificial chromosome (BAC) cloning (Lawrence et al. 1991).

The microsatellite marker order of the present comprehensive $\mathrm{RH}$ map is in good agreement with the linkage map by Kappes et al. (1997). Compared with the linkage map by Barendse et al. (1997) there are two disagreements: (1) our map separates the microsatellite MILSTS77 and the VIM gene by $17.2 \mathrm{cR}$, whereas the meiotic map treats the two loci as one marker, and (2) at the telomeric end of our comprehensive map the locus order is JAB3 - AGLA232 - telomere whereas the map by Barendse et al. (1997) has an inverted order for the former two loci. The telomeric part of the comprehensive RH map of BTA13 is in concordance with findings of a study that used clones of a bovine bacterial artificial chromosome (BAC) library (Cai et al. 1995) as probes to locate cytogenetically eight loci in this region of BTA13 (Schläpfer et al. 1997b). Our findings disagree with those of the male bovine linkage map (Ma et al. 1996), in that the order of marker pairs at both ends of the two maps is inverted. The study identifies TGLA6 as being telomeric to $B M C 1222$, which marks the most centromeric locus. A serious discrepancy is the order of centromere - URB58 - URB07, as these two loci are, in the order centromere - URB07 - URB58, in the RH framework map. However, the fact, that the two reversed marker pairs occur at the ends of the linkage map probably accounts for flipovers often seen in those locations.

Based on the analysis of our data set, we did not find the HSA20 homologous segment on BTA13 located centromeric to the HSA10 homologs IL2RA and VIM (Figure 3), as reported by three Zoo-FISH studies (Hayes 1995, Solinas-Toldo et al. 1995, Chowdhary et al. 1996). This is striking because loci representing both the p-arm (THBD, PRNP, GNAS1, HCK and PLC-II) and the q-arm (CSNK2A1, AVP and OXT) of HSA20 were incorporated in this study. As the three studies used human chromosome-specific DNA libraries as probes to 


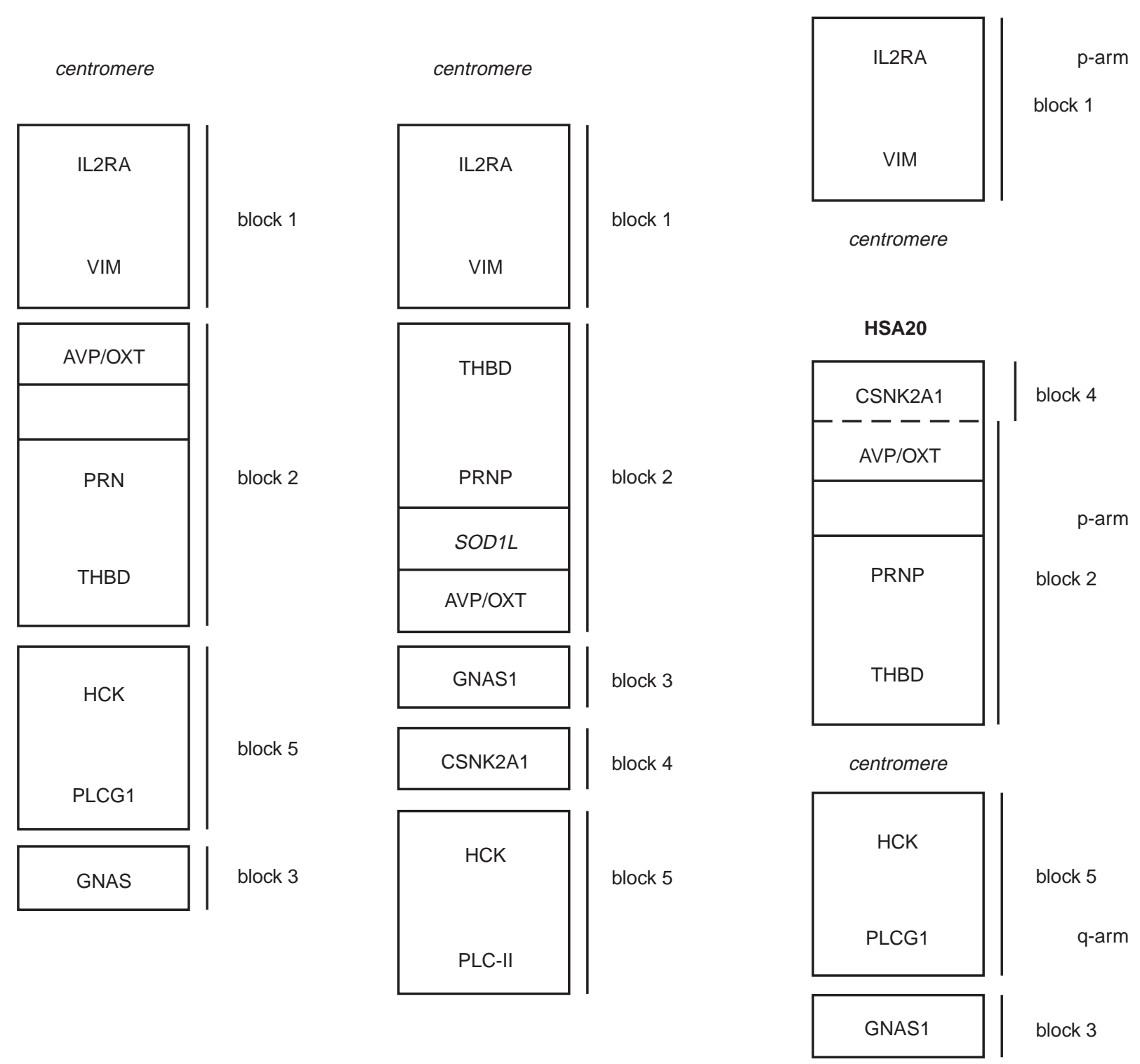

Figure 3. Five possible blocks of chromosomal rearrangement in cattle as compared with the human and mouse gene orders. The bovine PLC-II gene is homologous to the human PLCG1 locus and bovine PRNP corresponds to mouse $P R N$. No homologous gene to cattle SOD1L is known in man or mouse. CSNK2A1 is not yet assigned to a mouse chromosome.

hybridize to bovine chromosomes, the specific loci representing this HSA20 homologous segment on BTA13 are not known. Additional HSA20 comparative loci will have to be mapped on BTA13 to identify the HSA20 homologous loci of the centromeric region. Our findings, however, confirm a HSA20 segment telomeric to the two HSA10 loci, containing all of the remaining markers tested.

A goal of the present study was to describe blocks of conserved gene order between the bovine and human chromosome segments. All but two loci targeted in this study are represented on MMU2. To our knowledge, CSNK2A1 has not yet been assigned to MMU2 and no homolog to the bovine SOD1L locus has been identified yet in human or mouse. As $A V P / O X T$ were treated as one single locus during the $\mathrm{RH}$ analysis, our considerations involve only nine loci, two HSA10 and seven HSA20 homologs, or eight MMU2 homologous loci. Because CSNK2A1/AVP/OXT are merely cytogenetically mapped to HSA20p13, the linear gene order of the 


\section{J. Schläpfer et al.}

three loci is not known in human. The most parsimonious explanation would make CSNK2A1 the most telomeric of the three loci in human. Under this assumption we can define five conserved blocks between cattle and man (Figure 3). Block one consists of the HSA10 homologs IL2RA and VIM. All loci in the remaining four blocks are HSA20 homologs. Block two consists of THBD, PRNP, AVP/OXT, blocks three and four contain GNAS1 and CSNK2A1, respectively, and HCK and PLC-II make up block five. However, if the assumption of CSNK2A1 being the most telomeric of $A V P / O X T / C S N K 2 A 1$ in man is not correct, an additional block has to be postulated. Irrespective of this later point, it becomes evident that, although synteny is conserved between HSA10/HSA20 and BTA13, gene order within the homologous segments has been significantly altered by intrachromosomal rearrangements. This is also true compared with the gene order on MMU2. Similar results have been noted by Johansson et al. (1995), who found significant intrachromosomal rearrangements in conserved synteny groups of human and pig.

Our findings of five blocks of conserved locus order in cattle as compared with human and mouse homologous regions represent a basis for the subsequent high-resolution mapping necessary to enable the exploitation of the vast amount of information available from the map-rich human and mouse species for the 'comparative positional candidate cloning' (Womack \& Kata 1995) of ETLs. Because of the limited number of type I loci in this study, we consider these data as preliminary, and additional comparative genes have to be incorporated into the blocks in order to verify our findings. Blocks three and four await centromeric and telomeric expansion to define their end points and respective orientation on BTA13. Human homologous genes, that lie within the loci defining blocks one, two and three, have to be targeted and added to BTA13 to exclude possible subdivisions of these blocks.

Finally, the search for the loci representing the centromeric HSA20 homologs on BTA13, as found in ZOO-FISH studies, has to be emphasized. As RH analysis is an additive approach, promising new markers can be incorporated into an existing map as their sequences become available for PCR primer design and amplification. This will be especially true when the second WGRH panel, featuring a dosage of $12000 \mathrm{rad}$, which is currently being constructed in our lab, becomes available. This panel should allow the true marker order in marker-rich chromosomal regions to be resolved, clarify existing disagreements with other published maps and extending the comprehensive map presented.

However, this study demonstrates that WG-RHs are a powerful tool for integrating non-polymorphic, comparative loci with existing genetic maps. Although the resolution of the panel is limited if markers are clustered within specific chromosome regions, the 5000rad dosage has been shown to result in sufficient resolution power to construct a BTA13 framework map.

\section{Acknowledgements}

We thank Elaine Owens for her excellent cell culture work, Jan Johnson for the large-scale DNA extractions, and Srinivas Kata for the computer support. J.S. was supported by Swiss National Foundation grant 81BE043886 and by the Ciba-Geigy-Jubiläums-Stiftung. J.E.W. was supported by USDA grant 95-37205-2190 and by Texas Agricultural Experiment Station project 6718 .

\section{References}

Barendse W, Armitage SM, Kossarek LM et al. (1994) A genetic linkage map of the bovine genome. Nat Genet 6: 227-235.

Barendse W, Vaiman D, Kemp SJ et al. (1997) A mediumdensity genetic linkage map of the bovine genome. Mammalian Genome 8: 21-28.

Barrett JH (1992) Genetic mapping based on radiation hybrid data. Genomics 13: 95-103.

Bishop MD, Kappes SM, Keele JW et al. (1994) A genetic linkage map for cattle. Genetics 136: 619-639.

Boehnke M, Lange K, Cox CR (1991) Statistical methods for multipoint radiation hybrid mapping. Am J Hum Genet 49: 1174-1188.

Cai L, Taylor JF, Wing RA, Gallagher DS, Woo S-S, Davis SK (1995) Construction and characterization of a bovine bacterial artificial chromosome library. Genomics 29: 413-425.

Ceccherini I, Romeo G, Lawrence S et al. (1990) Construction of a map of chromosome 16 by using radiation hybrids. Proc Nat Acad Sci USA 89: 104-108.

Chowdhary BP, Frönicke L, Gustavsson I, Scherthan H (1996) Comparative analysis of the cattle and human genomes: detection of ZOO-FISH and gene mapping-based chromosomal homologies. Mammalian Genome 7: 297-302.

Collins FS (1995) Positional cloning moves from perditional to traditional. Nature Genet 9: 347-350.

Dib C, Faure S, Fizames C et al. (1996) A comprehensive genetic map of the human genome based on 5,264 microsatellites. Nature 380: 152-154.

Dietz AB, Neibergs HL, Womack JE (1992) Assignment of eight loci to bovine syntenic groups by use of PCR: extension of a comparative gene map. Mammalian Genome 3: 106-111.

Don RH, Cox PT, Wainwright BJ, Baker K, Mattick JS (1991) 'Touchdown' PCR to circumvent spurious priming during gene amplification. Nucleic Acids Res 19: 4008.

Gallagher DS, Gibbs LS, Shafer JB, Womack JE (1992) Somatic cell mapping of bovine EC-SOD and SOD1L loci. Genomics 12: $610-612$.

Gao Q (1996) Comparative mapping of the bovine genome: A multi-method approach targeting three gene families and bovine chromosome 7. Ph.D. Thesis, College Station, Texas: Texas A\&M University.

Gao Q, Womack JE (1993) Somatic cell mapping of five genes in cattle. Texas Genetics Society 20th annual meeting and the 4th meeting of TEXGENE, 21.

Gao Q, Lei L, Womack JE (1997) Assignment of the casein kinase II gene family to cattle chromosomes. Animal Genet 28: 146-149.

Goss SJ, Harris H (1975) New method for mapping genes in human chromosomes. Nature 255: 680-684.

Hayes H (1995) Chromosome painting with human chromosome-specific DNA libraries reveals the extent and distribution of conserved segments in bovine chromosomes. Cytogene Cell Genet 71: 168-174. 
Johansson M, Ellegren H, Andersson L (1995) Comparative mapping reveals extensive linkage conservation - but with gene order rearrangements - between the pig and human genomes. Genomics 25: 682-690.

Jones HB (1996) Hybrid selection as method of increasing mapping power for radiation hybrids. Genome Res 6: 761769.

Kappes SM, Keele JW, Stone RT et al. (1997) A secondgeneration linkage map of the bovine genome. Genome Res 7: 235-249.

Lange K, Boehnke M, Cox DR, Lunetta KL (1995) Statistical methods for polyploid radiation hybrid mapping. Genome Res 5: 136-150.

Lawrence S, Morton NE, Cox DR (1991) Radiation hybrid mapping. Proc Natl Acad Sci USA 88: 7477-7480.

Lenestra JA, van Boxtel JAF, Zwaagstra KA, Schwerin M (1993) Short interspersed nuclear element (SINE) sequences in the bovidae. Animal Genet 24: 33-39.

Lunetta KL, Boehnke M, Lange K, Cox DR (1995) Experimental design and error detection for polyploid radiation hybrid mapping. Genome Res 5: 151-163.

Ma RZ, Beever JE, Da T et al. (1996) A male linkage map of the cattle (Bos taurus) genome. J Hered 87: 261-271.

O'Brien SJ, Womack JE, Lyons LA, Moore KJ, Jenkins NA, Copeland NG (1993) Anchored reference loci for comparative genome mapping in mammals. Nature Genet 3: 103-112.

Raeymaekers P, Van Zand K, Jun L et al. (1995) A radiation hybrid map with 60 loci covering the entire short arm of chromosome 12. Genomics 29: 170-178.

Richard III CW, Withers DA, Meeker TC et al. (1991) A radiation hybrid map of the proximal long arm of human chromosome 11 containing the multiple endocrine neoplasia type I (MEN-I) and bcl-I disease loci. Am J Hum Genet 49: 1189-1196.

Schläpfer J, Kata SR, Amarante MRV, Womack JE (1997a) Syntenic assignment of thrombomodulin (THBD) and phos- phatidylinositol-specific phospholipase C (PLC-II) to bovine chromosome 13. Animal Genet 58: 308-309.

Schläpfer J, Gallagher Jr. DS, Burzlaff JD et al. (1997b) Comparative mapping of bovine chromosome 13 by fluorescence in situ hybridization. Animal Genet (in press).

Sefton L, Arnaud D, Goodfellow PN, Simmler MC, Avner P (1992) Characterization of the central region containing the $\mathrm{X}$-inactivation center and terminal region of the mouse $\mathrm{X}$ chromosome using irradiation and fusion gene transfer hybrids. Mamm Genome, 2: 21-31.

Solinas-Toldo S, Lengauer C, Fries R (1995) Comparative genome map of human and cattle. Genomics 27: 489-496.

Threadgill D, Womack JE (1991) Mapping HSA10 homologous loci in cattle. Cytogenet Cell Genet 57: 123-126.

Walter MA, Goodfellow PN (1993) Radiation hybrids: irradiation and fusion gene transfer. Trends Genet 9: 352-356.

Walter MA, Spillett DJ, Thomas P, Weissenbach J, Goodfellow PN (1994) A method for constructing radiation hybrid maps of whole genomes. Nature Genet 7: 22-28.

Warrington JA, Bailey SK, Armstrong E et al. (1992) A radiation hybrid map of 18 growth factor, growth factor receptor, hormone receptor, or neurotransmitter receptor genes on the distal region of the long arm of chromosome 5. Genomics 13: 803-808.

Womack JE, Moll YD (1986) Gene map of the cow: conservation of linkage with mouse and man. J Hered 77: 2-7.

Womack JE, Kata SR (1995) Bovine genome mapping: evolutionary inference and the power of comparative genomics. Current Opin Genet Dev 5: 725-733.

Womack JE, Dietz AB, Gallagher DS et al. (1991) Assignment of 47 additional comparative anchor loci to the bovine synteny map. Cytogenet Cell Genet 58: 2132.

Womack JE, Johnson JS, Owens EK, Rexroad III CE, Schläpfer J, Yang Y (1997) A whole genome radiation hybrid panel for bovine genome mapping. Mamm Genome (in press). 